\title{
LA DIMENSIÓN DE LA FORMACIÓN PERMANENTE DE DOCENTES QUE ACTÚAN EN ESCUELAS DE FRONTERA
}

\author{
A DIMENSÃO DA FORMAÇÃO PERMANENTE DE DOCENTES QUE ATUAM NAS \\ ESCOLAS DE FRONTEIRA
}

\section{THE DIMENSION OF PERMANENT TRAINING OF TEACHERS WHO WORK IN BORDER SCHOOLS}

\author{
Julio Emilio DINIZ-PEREIRA ${ }^{1}$ \\ Jorgelina Ivana TALLEI ${ }^{2}$
}

RESUMEN: El objetivo de este artículo es presentar algunos de los resultados de las acciones del programa de formación docente permanente Pedagogía de Frontera desarrollado entre los años 2016 y 2020 por la Universidad Federal de Integración Latinoamericana (UNILA), ofertado para las docentes de la red municipal de enseñanza en la ciudad de Foz de Iguazú, Paraná, Brasil. La metodología adoptada se basa en una perspectiva de investigación acción participativa desde el concepto del sociólogo colombiano Fals Borda. Los datos obtenidos a lo largo de la investigación demostraron que es posible planificar programas de formación docente permanente considerando el contexto trinacional. Las acciones formativas del programa permitieron reflexionar sobre el sentir de la frontera, estar en la frontera y pensar una educación de frontera. Este estudio se apoya en conceptos teóricos de autores como Bell Hooks, Paulo Freire, Orlando Fals Borda, Catherine Walsh, entre otros.

PALABRAS CLAVES: Formación docente permanente. Política educativa. Frontera.

RESUMO: O objetivo deste artigo é apresentar alguns dos resultados das ações do programa permanente de formação denominado Pedagogia de Fronteira, desenvolvido entre os anos 2016 e 2019, pela Universidade Federal da Integração Latinoamericana (UNILA) para os professores da rede municipal de ensino da cidade de Foz de Iguaçu, Paraná, Brasil. A metodologia adotada baseia-se em uma perspectiva de pesquisa-ação participativa, a partir do conceito do sociólogo colombiano Fals Borda. Os dados obtidos ao longo da pesquisa mostraram a possibilidade em planejar programas permanentes de formação, considerando o contexto trinacional. Mostram ainda que ações articuladas entre a comunidade escolar e as universidades públicas. As ações de formação do programa nos permitiram refletir sobre o que é estar na fronteira e pensar em uma educação na e para a fronteira. Este estudo é baseado em conceitos teóricos de autores como Diniz Pereira, Hooks, Freire, Fals Borda, Walsh, entre outros.

PALAVRAS-CHAVE: Formação permanente de professores. Politica educacional. Fronteira.

\footnotetext{
${ }^{1}$ Universidad Federal de Minas Gerais (UFMG), Belo Horizonte - MG - Brasil. Coordinador del Programa del Doctorado Latinoamericano Políticas públicas y profesión docente, de la Facultad de Educación (FaE). ORCID: https://orcid.org/0000-0002-5401-4788. E-mail: juliodiniz@fae.ufmg.br

${ }^{2}$ Universidad Federal de la Integración Latinoamericana (UNILA), Foz do Iguaçu - PR - Brasil. Docente de español como lengua adicional en el Instituto Latinoameriano de Artes, Cultura e Historia (ILAACH). ORCID: https://orcid.org/0000-0001-8486-0881. E-mail: jorgelina.tallei@unila.edu.br
} 
ABSTRACT: The purpose of this article is to present the in-service teacher education program called "Pedagogia de Frontera" (Border Pedagogy) developed between 2016 and 2020, for teachers who teach in the town of Foz do Iguaçu, at Brazil-Argentina-Paraguay border. The methodology is based upon a participatory action research perspective developed by the Colombian sociologist Fals Borda. The research data showed, on the one hand it is possible to plan in-service teacher education programs, considering the trinational context. The in-service teacher education program has allowed teachers to reflect upon the feeling of the border, to be on the border, and to think about education on the border. This study is based upon theoretical concepts coming from authors such as Bell Hooks, Paulo Freire, Orlando Fals Borda, Catherine Walsh, among others.

KEYWORDS: In-service teacher education. Education policies. Border.

\section{Introducción}

La formación docente tanto de carácter inicial o permanente ha sido objeto de estudio por diversos investigadores (CANÁRIO, 2013; DINIZ PEREIRA, 2010; 2011; GATTI, 2008; NÓVOA 1992; 1988; TARDIF, 2001; entre otros). De forma puntual, la formación docente permanente en la frontera, como caso de estudio, carece de investigaciones en el área. A partir de esta afirmación, este estudio, intenta describir y analizar un caso en concreto de formación docente permanente desarrollado en la frontera trinacional (Argentina, Brasil y Paraguay) a partir de detallado trabajo de doctorado ${ }^{3}$. Para tal, analizaremos la oferta de programa de formación permanente docente denominado Pedagogía de frontera ofertado para docentes de enseñanza básica de la red municipal de la ciudad de Foz de Iguazú en la frontera trinacional y diseñado desde la Universidad Federal de Integración Latinoamericana (UNILA). El programa es de carácter permanente y presencial e inicia sus actividades en el año 2016, presente hasta la actualidad, en colaboración con la Secretaria de Educación Municipal de la ciudad (SMED), la Universidad Estadual del Oeste de Paraná (UNIOESTE) y el Instituto Tecnológico Federal de Foz de Iguazú (IFPR). Durante todas las acciones formativas se realizaron observaciones, diarios de campo y análisis cualitativo y cuantitativo de datos. El hecho de escoger la ciudad de Foz de Iguazú como centro de esta investigación se debe a la ubicación de la UNILA y su misión estratégica basada en tres pilares: bilingüismo, interculturalidad e integración. Como parte de su misión estratégica la Universidad recibe a estudiantes de todos los países de América Latina y el Caribe, configurándose en una

${ }^{3}$ Tesis titulada: La dimensión política e intercultural en la formación docente permanente de docentes que actúan en escuelas de frontera: análisis del Programa "Pedagogía Intercultural" de la UNILA, orientada por el profesor Dr. Julio Emilio Diniz- Pereira, defendida en el año 2019 en la Universidad Federal de Minas Gerais (UFMG).

RIAEE - Revista Ibero-Americana de Estudos em Educação, Araraquara, v. 16, n. 4, p. 2263-2278, out./dez. 2021. e-ISSN: 1982-5587 
institución multilingüe y pluricultural. Por otro lado, la ciudad de Foz de Iguazú se posiciona de forma estratégica, según datos del Instituto Brasileño de Geografía y Estadística (IBGE) de 2017, tiene un área total de $617,71 \mathrm{~km}$ y se sitúa en lo que actualmente se define como la región de Alto Paraná. Además, registra cerca de $80^{4}$ grupos étnicos.

Esta configuración también se hace presente en las cincuenta (50) escuelas municipales de la ciudad. Prueba de ello, son los datos demolingüísticos ${ }^{5}$ recogidos en mayo de 2017 expresando que en ese momento se contaba con más de 355 (trescientos cincuenta y cinco) estudiantes matriculados en la enseñanza primaria, provenientes de países vecinos, Argentina, Paraguay y de diversos países como: Perú, México, España, entre los más destacados.

Entre marzo y julio del año 2019 los datos fueron actualizados mediante un levantamiento realizado en las cincuentas escuelas del municipio y arrojaron un número mayor de estudiantes de diversas nacionalidades que estudian, en la actualidad, en la red de enseñanza municipal primaria. Entre las nacionalidades se destacan: estudiantes provenientes de Paraguay, Argentina y Venezuela. Éstos últimos, especialmente, en la condición de refugiados.

A partir de este contexto, el programa de formación permanente Pedagogía de Frontera presenta diversas acciones formativas como cursos de formación, reuniones con las autoridades locales a fin de presentar resultados y debatir desafíos para la educación en la frontera considerando el contexto, elaboración de material didáctico para la enseñanza de lengua (español e inglés) a nivel primario y elaboración de un documento orientador para la recepción de estudiantes inmigrantes en la red municipal (FOZ DO IGUAÇU, 2020).

Antes de describir las diversas acciones del Programa, es importante señalar que ya en el año de 1992, el investigador Giroux (1992) ya nos proponía pensar en una pedagogía de frontera y como afirma Guilherme (2005, p. 140):

\footnotetext{
4 Datos de la Intendencia Municipal de Foz de Iguazú. Disponible en: http://www.pmfi.pr.gov.br/turismo/\%3Bjsessionid\% $\quad 3$ D74655f8fced39274db3e4138dcfb?idMenu=1695. Acceso: 2 jun. 2020.

${ }^{5}$ Los datos se obtuvieron mediante presentación formal (oficio) para la Secretaría de Educación Municipal de Foz de Iguazú, entendiendo que era fundamental conocer la situación para la planificación y puesta en marcha del programa de formación docente del año 2018. Por otro lado, es importante resaltar que la SMED no disponía de estos datos hasta el momento. Este número puede variar de acuerdo con los registros de las secretarías de cada escuela. Según documento orientador (Secretaria de educação municipal et all, 2020, p.10) A demolinguística ou demografia linguística tem como finalidade mensurar a magnitude dos grupos linguísticos em territórios e momentos determinados [...]. Cabe ressaltar ainda que os resultados obtidos através do cruzamento de variáveis sociolinguísticas e demográficas (delimitações territoriais, idade, origem geográfica, nível de escolarização, etc.), além de permitir a divulgação de informações relevantes a respeito do grau de aquisição e usos das diferentes línguas presentes na comunidade, possibilita, do ponto de vista da gestão educativa, avaliar, aprimorar e propor políticas linguísticas que garantam o direito à educação, criando condições efetivas de acesso, permanência e sucesso escolar.
} 
A sua proposta pode ser entendida como a aplicação de uma perspectiva cosmopolita pós-colonial à noção norte-americana de educação cívica democrática. Giroux elabora uma visão para a educação que corresponde aos desafios que se apresentam, no início deste século XXI, às sociedades ocidentais e que decorrem das profundas mudanças demográficas e políticas pelas quais elas estão a passar na atualidade.

En base a la perspectiva de Giroux, y tomando el concepto de pedagogía de frontera partiendo de su carácter territorial y pluricultural nuestra propuesta es entender la Triple Frontera como el territorio del entre lugar (BHABHA, 2014) o si se prefiere como un entre orillas en metáfora directa con el Río Paraná que bordea la Triple Frontera. En la perspectiva del autor, el concepto de in-between:

[...] o trabalho fronteiriço da cultura exige um encontro com "o novo" que não seja parte do continuum de passado e presente. Ele cria uma ideia do novo como ato insurgente de tradução cultural. Essa arte não apenas retoma o passado como causa social ou precedente estético ela renova o passado, refigurando-o como um entre-lugar contingente, que inova e interrompe a atuação do presente. O passado-presente torna-se parte da necessidade, e não da nostalgia, de viver (BHABHA 2014, p. 21).

Desde el entre lugar se producen diversas grietas o intersticios, espacios de conflictos que generan tensiones, pero también son lugares de perspectivas porque es a partir de allí que pueden surgir esperanzas (WALSH, 2014). A partir de las grietas reflexionamos sobre una pedagogía de frontera o una pedagogía sentipensante para América Latina ${ }^{6}$, proponiendo prácticas de formación docente permanente en contextos invisibilizados por el poder central.

\section{Acciones del Programa Pedagogía de Frontera}

En el año 2016 el programa se inicia destinado a pensar aspectos que permean la cotidianidad fronteriza en las escuelas. El primer año se inicia motivado por un grupo de docentes investigadoras de la UNILA preocupadas con la formación docente desde el contexto trinacional. Ese año, trabajamos a partir de dibujos, mapas, reflexiones, lo afectivo de vivir y estar en la frontera partiendo de reflexiones sobre el concepto de frontera y el estar en la frontera desde el lugar que las docentes ${ }^{7}$ ocupan como habitantes de la ciudad. Las

\footnotetext{
${ }^{6}$ Entendemos como prácticas sentipensantes aquellas que saben conjugar la razón con el corazón. Al pensar en prácticas sentipensantes entendemos que las culturas siempre son dinámicas y que en el espacio escolar surgen nuevas estrategias de sentido que desafían la lógica monocultural y la hegemonía de la cultura dominante. Las prácticas sentipensantes pueden ser pensadas determinando las estrategias formativas en los programas de formación docente de carácter permanente.

${ }^{7}$ Usamos el femenino para designar a las participantes ya que el 98\% de ellas fueron/son mujeres.
}

RIAEE - Revista Ibero-Americana de Estudos em Educação, Araraquara, v. 16, n. 4, p. 2263-2278, out./dez. 2021. e-ISSN: 1982-5587 
docentes participantes del año 2016 reflexionaron sobre conceptos de frontera, interculturalidad y lenguas en las escuelas. Consideramos este año importante puesto que se llevó a cabo la implantación del programa de formación permanente donde se realizó una importante sensibilización en el total de cincuenta (50) escuelas de la ciudad, teniendo en cuenta que hubo una participación importante de las docentes.

Ya en el año de 2017 nos concentramos en trabajar a partir de conceptos que nos permitan entender la escuela como institución de frontera. Para tal, fueron realizados encuentros en escuelas específicas seleccionadas por la fuerte presencia de estudiantes inmigrantes. Este año, se discutieron los documentos oficiales del municipio, como el documento curricular de las escuelas municipales de Foz de Iguazú y el Plan de educación municipal, en la reflexión de conceptos claves: frontera, lengua e interculturalidad. Buscábamos entender el lugar (o no lugar) de los estudiantes inmigrantes en las políticas públicas educativos del municipio y de la provincia de Paraná. Intentamos, también, una aproximación en las escuelas de Puerto Iguazú (Argentina), ciudad frontera con Foz de Iguazú, y con Ciudad del Este, del lado de Paraguay, sin embargo, no conseguimos llevar a cabo un programa conjunto debido a la burocracia interna de los respectivos países para cruzar la frontera, entre uno de los puntos más destacados.

Además, realizamos un análisis demolingüístico en las cincuenta (50) escuelas municipales, con el objetivo de mensurar las lenguas presentes en el espacio escolar y concentrar las acciones de formación docente a partir de las necesidades de cada escuela.

En el año 2018, las acciones se concentraron en el área de educación lingüística, con programas de formación en español e inglés para las docentes del municipio, especialmente las que actúan en la enseñanza primaria.

Estos dos últimos años fueron claves para el análisis de los datos, la presentación de proyectos de extensión y de investigación ligados a la temática de educación intercultural y multilingüe en la frontera.

En 2019, se implementaron dos proyectos pilotos de enseñanza de español e inglés como lenguas adicionales, en dos escuelas municipales de enseñanza primaria de la ciudad. Tal propuesta, tenía la intención de provocar, en la comunidad del barrio, una sensibilidad hacia el reconocimiento de las lenguas en el contexto escolar para así ganar apoyo en la futura implementación de lenguas en las escuelas ${ }^{8}$. Este año actualizamos los datos demolingüísticos en las escuelas a partir de implementación de cuestionario aplicado en las cincuentas escuelas.

${ }^{8}$ En el año de 2020 varios candidatos a concejales e intendentes de la ciudad se comprometieron con la pauta de implementación de lenguas en las escuelas municipales. 
El programa ganó fuerza en la ciudad y se constituye hoy, como un programa de referencia, en el 2018 ganó un premio internacional como práctica innovadora ${ }^{9}$.

\section{Acciones formativas: un análisis de los documentos oficiales}

En diversas acciones de formación que tuvieron lugar en el programa analizamos documentos oficiales, a fin de intentar diseñar el lugar que ocupa el concepto fronterizo/sujeto de frontera en las políticas educativas de formación docente de la ciudad de Foz de Iguazú y en el contexto nacional. Observamos que en los documentos oficiales el sujeto fronterizo es silenciado, al analizar, por ejemplo, la Política Nacional de Formación de los profesionales de educación básica (2016) no se vislumbran aspectos que levanten la cuestión sobre formación docente en la frontera. Lo mismo sucede en el documento de la Ley de Bases y Directrices de la Educación (2017) donde no hay mención al sujeto fronterizo. El plano Nacional de Educación (2014-2024) en Brasil, refiere a conceptos como diversidad, cultura e igualdad, sin embargo también se omite en relación al concepto específico de frontera y las particularidades educativas de ese contexto.

A nivel nacional, uno de los primeros documentos y el único al posicionar en el centro al sujeto fronterizo es el documento marco del Programa de Escuelas Interculturales de frontera (PEIF). El Programa nació de la necesidad de estrechar lazos interculturales entre ciudades vecinas que forman frontera con Brasil, como lo expone el Documento Marco Referencia de Desarrollo Curricular (2012). Con el objetivo de estrechar los lazos en el área educativa se firmó en Argentina, en el año 2003, la Declaración Conjunta de Brasilia para el fortalecimiento de la integración regional entre los Ministerios de Educación de Brasil y de Argentina. Y en el año 2004 se elabora el primer plan de trabajo conjunto, denominado: "Modelo de enseñanza común en escuelas de zona de frontera", a partir del desarrollo de un programa para la educación intercultural, con énfasis en la enseñanza del portugués y del español. Posteriormente, en el año 2005, se inicia como un programa bilateral y en el año de 2007 se consolida como un programa de la Secretaria Educativa del Mercosur, donde se incluye a los países de Bolivia, Paraguay, Uruguay y Venezuela.

Paiva (2016, p. 177) presenta un breve recorrido de inicio del PEIF en la ciudad de Foz de Iguazú:

9 La propuesta puede ser observada en el siguiente enlace. Disponible en: https://desarrollodocente.org/es/experiences/49?public=true. Acceso: 15 nov. 2020

RIAEE - Revista Ibero-Americana de Estudos em Educação, Araraquara, v. 16, n. 4, p. 2263-2278, out./dez. 2021. e-ISSN: $1982-5587$ 
Sobre a estrutura do programa, o relatório produzido pela Secretaria Municipal da Educação de Foz do Iguaçu na ocasião da primeira reunião entre a equipe dos dois países, em abril de 2006, destaca os principais acordos para a implementação do programa nas escolas: - Inicialmente o projeto atenderia duas turmas do ensino fundamental de cada instituição no turno da tarde, todas as quartas-feiras; - As aulas bilíngues seriam ministradas no período contra turno; - A metodologia escolhida foi a de projetos pedagógicos interculturais; - A cada quinze dias os planejamentos das aulas seriam feitos com os professores envolvidos no projeto, com alternância dos turnos de encontro e das escolas.

El Programa cesó sus actividades en el año de 2016 como política vinculada al Ministerio de Educación (MEC Brasil), aunque algunas escuelas de las diferentes ciudades de frontera, a lo largo de todo el territorio brasilero, lo han mantenido con recursos presupuestarios propios, o con esfuerzos de las universidades públicas locales que participaron del PEIF, tal es el caso de la SMED y la UNILA, por ejemplo.

Otro documento importante con una propuesta asertiva sobre las realidades que se materializan en la frontera es el documento propuesto por el Grupo de trabajo formación Docente da SEB/MEC: Orientações para cursos de Formação de Professores nas áreas de Didática, Metodologias e Práticas de Ensino (2016) ya que propone identificar cuestiones y problemas socioculturales y educativas, con postura investigativa, integrativa y propositiva en las realidades complejas, a fin de contribuir para la superación de exclusiones sociales, étnicoraciales, económicas, culturales, religiosas, políticas, de género, sexuales y otras. A pesar de no traer cuestiones específicas sobre las realidades de frontera, manifiestan puntos claves para el diseño de una política educativa llevando en consideración temáticas que atraviesan las realidades de las escuelas de frontera.

De reciente aprobación, las Directrices Curriculares Nacionales para la oferta de educación plurilingüe, aprobadas en septiembre de 2020 por el Consejo de Educación Básica de Brasil, propone un apartado sobre las características de la educación en la frontera considerando el contexto multilingüe presente en las regiones fronterizas. Aunque es de destacar que el documento apenas intenta dar cuenta de algunos aspectos de la configuración en la frontera, sin propuestas concretas. Las escuelas, una vez apropiadas del documento, deberán proponer propuestas específicas llevando en consideración sus características que le son propias. 


\section{Documentos oficiales en el ámbito municipal: el sujeto fronterizo}

Uno de los documentos más importantes en el ámbito municipal, es el Plan Municipal de Educación 2014/2025 (2015). En el mismo están enunciadas las directrices y compromisos con la educación municipal durante diez años. A lo largo de esos años, el plan municipal de educación es monitoreado por el Foro Municipal que verifica los objetivos, desafíos y perspectivas para cada directriz. El documento no coloco en el centro el sujeto fronterizo, apenas enuncia y de forma tímida algunas cuestiones relativas a la: "III - superação das desigualdades educacionais, com ênfase na promoção da cidadania e na erradicação de toda as formas de discriminação" (p. 3).

El documento enuncia entre sus metas, temáticas que permiten vislumbrar posibles acciones de importancia para la formación docente de carácter permanente y el contexto de frontera. Se emite en el documento:

[...] Minimizar as desigualdades e discriminações existentes no cotidiano escolar e despertar o respeito a diversidade embasados nos princípios dos Direitos Humanos. 8.11) Criar um projeto anual em parceria com a Secretaria Municipal da Educação, para trabalhar os temas referentes à diversidade no período do ano letivo na Rede Municipal de ensino em parceria com universidades do Município 8.12) Promover encontros, fóruns, debates que possibilitem a revisão dos conteúdos necessários para abordagem do tema "Educação em Direitos Humanos".8.14) Produzir material didático pedagógico sobre diversidade cultural, desigualdade e discriminação que apoie os professores nas atividades cotidianas em sala de aula. 8.15) Acompanhamento cotidiano das relações entre estudantes, para erradicar todas as formas de discriminação (PLAN MUNICIPAL DE EDUCACIÓN, 2015, p. 4).

De cierta forma se presuponen temáticas que permean el concepto de interculturalidad y frontera, pero el documento no se refiere de manera específica y clara a una educación para las fronteras y tampoco se observa un tratamiento de la realidad de la red de escuelas municipales teniendo en cuenta la temática intercultural y lingüística, considerando la realidad multilingüe que arrojaron los datos obtenidos a partir de los análisis demolingüísticos realizados.

En las escuelas se observa un flujo fronterizo importante y la presencia de estudiantes de un lado y otro de la frontera es constante, si consideramos los datos del año 2019 de estudiantes inmigrantes matriculados en la enseñanza primaria, ese número significa más del 2,5\% de la totalidad de la red.

En análisis realizado en el año de 2019, mediante aplicación de cuestionario en todas las escuelas de red básica municipal, observamos que las escuelas ya disponen de 
profesionales graduados tanto en la lengua española como también en lengua inglesa, o sea, capaces de ofertar materias en esas lenguas, ya sea por medio de implementación de las lenguas en el currículo del municipio, o la posibilidad de planificar contenidos interdisciplinares y multilingües para los/as estudiantes teniendo en cuenta el derecho a educación de todos los sujetos que frecuentan la escuela.

El concepto de frontera, o la planificación de políticas públicas que trabajen ese escenario multicultural y diverso enunciado por las docentes, está ausente en los documentos oficiales de formación permanente en la SMED. Esta ausencia deja al margen a las personas que construyen otras subjetividades desde los entre lugares fronterizos, olvidados y en el margen terminan, muchas veces, invisibilizados en las políticas públicas educativas.

\section{Programa de formación permanente de docentes: acciones de formación docente permanente}

A partir de observar la invisibilización de estas políticas organizamos el programa de formación docente permanente: Pedagogía de Frontera. Para tal planificación, nos posicionamos a partir de entender el concepto de formación docente permanente desde el concepto propuesto por Cachapuz (2003) y Diniz-Pereira (2011). El primer autor afirma que uno de los tantos legados que el último siglo nos dejó en relación a la formación docente permanente se refiere a tres perspectivas, siendo el constructivismo, la reflexión y la interacción con la comunidad, entendiendo la formación docente permanente desde los diferentes saberes. Para el autor:

O traço essencial da mudança de que precisamos passa por uma lógica de formação contínua centrada no complemento de saberes proporcionados pela formação inicial (isto é, o que ficou pelo caminho ou se tornou obsoleto) frequentemente levada a cabo com base em iniciativas avulsas e não poucas vezes servindo mais os interesses das instituições de formação do que os professores a quem ela se dirige - para uma lógica de aprendizagem ao longo da vida articulando harmoniosamente saberes académicos e epistemologias das práticas dos professores, lógica essa implicando necessariamente uma visão sistémica da formação (CACHAPUZ, 2003, p. 453).

Entendemos que el autor al referirse a una visión sistémica de la formación tiene en cuenta los saberes docentes, las políticas educativas, la formación inicial, y la gestión, desde una visión que envuelva los saberes docentes. Este concepto se enlaza con la propuesta de racionalidad crítica, propuesta por Diniz-Pereira (2011, p. 27). El autor al referirse a la formación inicial describe tres modelos que se basan en la propuesta de una racionalidad 
crítica: "el modelo socio-constructivista; el modelo emancipador o transgresor y el modelo ecológico crítico". Modelos que, de cierta forma, están asociados a la concepción freiriana:

O que me interessa agora, repito, é alinhar e discutir alguns saberes fundamentais à prática educativo-crítica ou progressista e que, por isso mesmo, devem ser conteúdos obrigatórios à organização programática da formação docente. Conteúdos cuja compreensão, tão clara e tão lúcida quanto possível, deve ser elaborada na prática formadora. É preciso, sobretudo, e aí já vai um destes saberes indispensáveis, que o formando, desde o princípio mesmo de sua experiência formadora, assumindo-se como sujeito também da produção do saber, se convença definitivamente de que ensinar não é transferir conhecimento, mas criar as possibilidades para a sua produção ou a sua construção (FREIRE, 1996, p. 12).

Esta concepción está unida a la propuesta del sociólogo colombiano Fals Borda (1986) al pensar la acción participativa desde el carácter social de transformación del territorio y se enmarca en la metodología adoptada por el programa pedagogía de frontera. Para Fals Borda, esta condición se relaciona con la identidad, al ir viviendo, y al reconocimiento como personas transformadoras.

[...] la relación participativa de sujeto/sujeto obviamente rompe las relaciones de subordinación, explotación, opresión y manipulación que aparecen en nuestras sociedades en muchos aspectos de la vida cotidiana [...] la familia (machismo, paternalismo), la educación (magister dixit), la medicina (enfermo-cliente), la economía (el trabajador-máquina) y, por supuesto, también a la política. En este caso, se rompen las tradicionales relaciones impositivas del caudillo (gamonal, coronel, cacique) sobre su cauda, las de las maquinarias de los dirigentes sobre los dirigidos, y también los mecanismos de imposición de vanguardias soberbias sobre las bases a las que han considerado como masas moldeables, a las que llevan el monopolio sectario de su verdad (FALS BORDA, 1986, p. 11).

La propuesta de investigación acción participativa del autor es una apuesta importante en el programa de formación docente permanente, al entender que son las docentes de las escuelas como agentes transformadoras del territorio en construcción colaborativa las que deben elaborar, planificar y evaluar el programa pedagogía de frontera.

Y para cumplir con ese objetivo, alineado a la metodología propuesta, en el 2017 organizamos grupos de debate entre docentes del municipio participantes del programa de formación, docentes pesquisidoras, representantes de la SMED y formadoras del grupo Pedagogía de frontera para pensar las temáticas y acciones que serían debatidas en el ámbito del programa. A partir de los diversos debates tres grandes ejes fueron propuestos para trabajar las diversas acciones del programa: lengua, interculturalidad y frontera. 
Así, a partir de los debates las acciones de formación, intentaron, organizarse de acuerdo a esos tres grandes ejes. En el eje lingüístico, de lenguas, las docentes enunciaban los desafíos de recibir a estudiantes de diversas nacionalidades y la inseguridad de no poseer fluencia en la lengua (español o inglés, dadas las nacionalidades de los estudiantes con mayor flujo migratorio en las escuelas). De esta forma, se organizó en los años de 2018 y 2019 la oferta de cursos de español para las docentes del municipio. El curso también se extendió a trabajadores/as de la Secretaria de Asistencia Municipal, entendiendo la importancia del trabajo en colaboración y conjunto en la temática inmigratoria.

Durante todo ese año, observamos a partir de las acciones de formación y la interacción con la comunidad escolar de diversas escuelas municipales, que en relación a las diferentes culturas presentes en la ciudad y en las escuelas se reproducen discursos de cierta negación y aún falta avanzar para una verdadera interacción. "Esa aceptación mutua" (enunciada en el discurso de una de las docentes participantes del programa de formación), reafirma la cultura dominante superior ("hay una cierta tentativa de comunicación") con la idea de una interculturalidad que está vinculada a la idea de tolerancia, pero que no avanza hacia el diálogo democrático e equitativo.

Esta relación que se establece en las escuelas y que se percibe por parte de parte de las docentes cuando hablamos de estudiantes inmigrantes, condice también con la imposición de una lengua oficial (el portugués) y la ausencia de políticas educativas para las fronteras. En este proceso la escuela cumple un papel esencial fabricando y (re)creando la idea de la nación en el espacio escolar. Por otro lado, se impone el pensamiento colonial: o desde el silenciamiento del otro o desde la condición de otorgarle el mismo lugar, sin considerar las diversas diferencias.

En ese intento, hacia una política educativa de frontera, el año de 2018, concentró el debate de las acciones en la realización de talleres formativos en las escuelas para debatir temáticas a partir de los tres ejes enunciados por las docentes.

Como parte de las estrategias metodológicas, este año se realizando diarios de campos, y los relatos de las docentes exteriorizaron una realidad que viven cotidianamente y que se relaciona con el silenciamiento que los estudiantes también viven, obligándolos, en muchas ocasiones, a desterriorilizar (se) dentro del espacio escolar. La falta de implementación de las lenguas adicionales en el currículo, materializa la ausencia de políticas lingüísticas en el municipio y en la provincia, y muchos de los estudiantes inmigrantes que estudian en las escuelas son colocados en lo que se denomina de "reforço especial ou aulas especiais" porque no logran, según los relatos docentes, acompañar las clases. De esta forma, son 
completamente invisibilizados o, colocados en un entre lugar que no vislumbra la posibilidad de esperanzas, sino por el contrario, profundiza situaciones de violencia simbólica y lingüística.

Colocar en debate estas temáticas implica poder cruzar las barreras lingüísticas existentes en los espacios escolares y desmitificar, de cierta forma, el imaginario de una ciudad que se proyecta multicultural y plurilingüe para el turismo, para el comercio, para las relaciones del capital económico, pero al diseñar las políticas educativas considera fundamental cumplir con índices académicos sin considerar la lengua y la cultura de todos los estudiantes de la red.

También en los diversos diarios de campo, la responsabilidad en la institución educativa por promover un ambiente intercultural aparecía a través de una actitud crítica y abierta, de cierta forma acogedora, este aspecto puede resultar positivo o negativo. Como apunta Hooks (2013, p. 52):

[...] apesar do multiculturalismo estar atualmente em foco em nossa sociedade, especialmente na educação, não há, nem de longe, discussões práticas suficientes acerca de como o contexto da sala de aula pode ser transformado de modo a se fazer do aprendizado uma experiência de inclusão.

Para la autora, una educación pautada en esta línea debe promover prácticas interculturales que se propongan descontruir sistemas y rescata la importancia de trabajar desde una perspectiva amorosa, desde el afecto.

Consideremos que es posible pensar desde el paradigma del afecto, o sentipensante (FALS BORDA, 1986) cuando reflexionamos en la planificación del programa Pedagogía de Frontera, ya que las propias docentes participantes enunciaron que era fundamental debatir el lugar de acogida de los estudiantes inmigrantes, teniendo en cuenta los más diversos discursos de prejuicios que circulan en la ciudad y en las escuelas, como así también la falta/ausencia de políticas educativas que coloquen en el centro el sujeto fronterizo.

Destacamos, además, que como parte de las acciones formativas del programa también se realizan desde 2017 acciones con los concejales municipales, así como con el intendente y secretarias municipales, a fin de trasformar, de hecho, el territorio, en la valorización de todos los sujetos. 


\section{Consideraciones finales}

El trabajo realizado durante 2016 nos permitió observar y reflexionar que el municipio debe poner atención a la temática educativa inmigratoria. Para tal, una de las acciones que pueden ser realizadas es la creación de un sector específico en la SMED, para trabajar la memoria histórica de sus estudiantes inmigrantes, reconociéndolos como personas con plenos derechos, otorgándoles lugar en sus políticas públicas educativas.

Al pensar en los programas de formación docente permanente, los mismos deben posibilitar una reflexión desde las diversas temáticas que atraviesan las condiciones de las docentes fronterizas en interrelación con los procesos históricos, sociales y culturales del territorio desde el lugar afectivo que la frontera también ocupa. Deben considerar un lugar pluricultural, si se prefiere un entre lugar, que posibilite el reconocimiento de la interculturalidad desde el lugar de frontera, diferente de otros procesos interculturales y que además se corresponda de forma singular con las realidades de cada frontera. En ese entre lugar, es posible pensar o diseñar lugares de esperanzas para transformar realidades fronterizas. Muchas de las docentes que participan del programa de formación contemplan la posibilidad de nuevos sentidos a partir del contacto de las culturas, a partir del diálogo y la solidaridad.

Como mencionamos en el trabajo, en el año de 2019 caminamos hacia la planificación e implementación de lenguas en las escuelas municipales con dos proyectos pilotos, sin embargo aún nos enfrentamos con diversas resistencias que provienen de paradigmas entre lenguas consideradas de prestigio, como el inglés y lenguas minorizadas, como el guaraní, lengua oficinal de Paraguay y lengua materna de muchos estudiantes de la red municipal y también el español, a pesar de ser/estar en la frontera, estos idiomas son minorizados en las escuelas y en las diversas gestiones municipales de la ciudad de Foz de Iguazú.

La ciudad de Foz de Iguazú es multicultural y diversa pero debe avanzar hacia el camino de una ciudad pluricultural y multilingüe, en todos los sectores y segmentos de sus instituciones. En este sentido, tal vez, un camino posible para la formación docente permanente en la frontera sea partir de una pedagogía sentipensante, esto es, en la sensibilización de los problemas que enfrentan las docentes que actúan en la frontera, a partir de la empatía, entendida desde el lugar de la equidad y la solidaridad, en el equilibrio de la razón y el corazón en la construcción crítica del pensamiento hacia el camino de una educación transformadora y democrática. 


\section{REFERENCIAS}

BHABHA, H. K. O local da cultura. Belo Horizonte, MG: Editora UFMG, 2014[1994].

BRASIL. Lei n. 9.394, de 20 de dezembro de 1996. Estabelece as diretrizes e bases da Educação nacional. Brasília, DF, 23 dez. 1996. Disponible:

http://www.planalto.gov.br/ccivil_03/leis/19394.htm. Acceso: 20 dic. 2020.

BRASIL. Lei n. 13.005, de 25 de junho de 2014. Plano Nacional de Educação. Brasília, DF, 26 jun. 2014. Disponible: http://pne.mec.gov.br/18-planos-subnacionais-de-educacao/543plano-nacional-de-educacao-lei-n-13-005-2014. Acceso: 19 dic. 2020.

BRASIL. Decreto n. 8.752, de 9 de maio de 2016. Dispõe sobre a Política Nacional de Formação dos Professionais de Educação Básica. Brasília, 10 maio 2016. Disponible http://www.planalto.gov.br/ccivil_03/_Ato2015-2018/2016/Decreto/D8752.htm. Acceso: 20 dic. 2020

BRASIL. Comissão SEB/MEC. Orientações para cursos de formação de professores nas áreas de didática, metodologias e práticas de ensino. Brasília, DF, fev. 2016. Disponible en: http://portal.mec.gov.br/index.php?option=com_docman\&view=download\&alias $=40811$ documento-base-fevereiro-2016-pdf\&category_slug=maio-2016-pdf\&Itemid=30192. Acceso: 15 nov. 2020.

BRASIL. Conselho Nacional De Educação. Diretrizes Curriculares Nacionais para a oferta de Educação Plurilíngue. Brasília, DF: CNE, 2020. Disponible:

http://portal.mec.gov.br/index.php?option=com_docman\&view=download\&alias $=156861$ pceb002-20\&category_slug=setembro-2020-pdf\&Itemid=30192. Acceso: 15 nov. 2020.

CACHAPUZ, A. F. "Do que temos, do que podemos ter e temos direito a ter na formação de professores: em defesa de uma formação em contexto". In: BARBOSA, R. L. L. (org.).

Formação de educadores: desafios e perspectivas. São Paulo: Editora UNESP, 2003. p. 451-464.

CANÁRIO, R. Educação de adultos: um campo e uma problemática. Lisboa: Educa, 2013.

DINIZ-PEREIRA, J. E. A pesquisa dos educadores como estratégia para a construção de modelos críticos de formação docente. In: DINIZ-PEREIRA, J. E.; ZEICHNER, K. (org.). A pesquisa na formação e no trabalho docente. São Paulo: Autêntica, 2011. p. 11-42.

DINIZ-PEREIRA, J. E. Formação continuada de professores (verbete). In: Dicionário: trabalho, profissão e condição docente. Belo Horizonte: UFMG/Faculdade de Educação, 2010. CDROM.

FALS BORDA, O. Reflexiones sobre democracia y participación. Revista Mexicana de Sociología, v. 48, n. 3, p. 7-14, 1986.

FOZ DO IGUAÇU. Lei n. 4.341, de 22 de junho de 2015. Plano de Educação Municipal de Foz do Iguaçu. Foz do Iguaçu, PR: Secretaria de Educação Municipal, 2015. 
FOZ DO IGUAÇU. Secretaria Municipal de Educação, Grupo de Pesquisa Língua (GEM), Política e Cidadania, da Universidade Federal da Integração Latinoamericana (UNILA). Protocolo de acolhimento de estudantes imigrantes na rede municipal de ensino. Foz do Iguaçu, PR: SEMD, 2020. Disponible:

https://dspace.unila.edu.br/bitstream/handle/123456789/5879/DOCUMENTO\%20ORIENTA

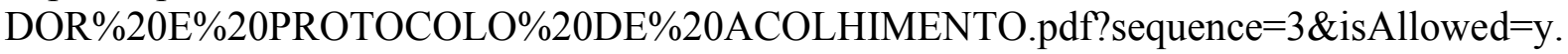
Acceso: 20 dic. 2020

FREIRE, P. Pedagogia da autonomia: saberes necessários à prática educativa. 24. ed. Rio de Janeiro: Paz e Terra, 1996.

GATTI, B. A. Análise das políticas públicas para formação continuada no Brasil, na última década. Revista Brasileira de Educação, v. 13, n. 37, p. 57-70, jan./abr. 2008.

GIROUX, H. A. La pedagogía de frontera y la política del posmodernismo. Revista Intringulis, n. 6, p. 37-42, sep./dic. 1992.

GUILHERME, M. Qual o papel da pedagogia crítica nos estudos da língua e a cultura? Revista Crítica de Ciências Sociais, v. 73, p. 131-143, 2005.

HOOKS, B. Ensinando a transgredir: a educação como prática da liberdade. Trad. Marcelo Brandão Cipolla. São Paulo: Martins Fontes, 2013.

MERCOSUR. Escuelas de Frontera. Documento Marco Referencial de Desarrollo Curricular. 2012.

NÓVOA, A. A formação tem de passar por aqui: as histórias de vida no projecto Prosalus. In: NÓVOA, A.; FINGER, M. (org.). O método (auto)biográfico e a formação. Lisboa: Ministério de Saúde, 1988.

NÓVOA, A. "Os professores e a história da sua vida". In: NÓVOA, A. (org.). Vidas de professores. Porto: Porto Editora, 1992.

PAIVA, A. C. Políticas educacionais para a diversidade e escolas na fronteira: o caso de Foz de Iguaçu com a Argentina e o Paraguai. 2016. 142 f. Dissertação (Mestrado em Sociedade, Cultura e Fronteiras) - Universidade Estadual do Oeste de Paraná, Foz do Iguaçu, 2016.

RODRIGUES DE ARAUJO, V. Saber quem se é: uma proposta pedagógica decolonial e sentipensante. Revista SURES, n. 9, p. 71-84, feb. 2017. Disponible:

https://ojs.unila.edu.br/ojs/index.php/sures. Acceso: 15 dic. 2020.

TARDIF, M. Apresentação. Revista: Educação e Sociedade, Campinas, v. 22, n. 74, p. 11 26, abr. 2001.

WALSH, C. Interculturalidad, conocimiento y decolonialidad. Rev.Signo y pensamiento, v. 46, v. 24, p. 39-50, ene./jun. 2005. 


\section{Cómo referenciar este artículo}

DINIZ-PEREIRA, J. E.; TALLEI, J. I. La dimensión de la formación permanente de docentes que actúan en escuelas de frontera. Revista Ibero-Americana de Estudos em Educação, Araraquara, v. 16, n. 4, p. 2263-2278, out./dez. 2021. e-ISSN: 1982-5587. DOI: https://doi.org/10.21723/riaee.v16i4.14941

Enviado: $28 / 03 / 2021$

Revisiones necesarias: $20 / 06 / 2021$

Aprobado: 26/08/2021

Publicado: $21 / 10 / 2021$ 